\title{
INFLUENCIA DEL PROFESORADO EN LA INTEGRACIÓN ESCOLAR DEL ALUMNADO MINORITARIO
}

\section{The influence of the teachers on minoritary student's school integration}

\section{José Antonio JORDÁN SIERRA}

Universidad Autónoma de Barcelona. Facultad de la Educación. Edificio G-6.

Departamento de Pedagogía Sistemática y Social. 08193 Bellaterra. Barcelona.

Correo-e: josep.jordan@uab.es

Fecha de aceptación definitiva: marzo de 2001

BIBLID [(1130-3743) 12, 2000, 67-83]

\section{RESUMEN}

En este estudio se realiza un análisis de la gran influencia que los profesores ejercen sobre la integración escolar de los alumnos culturalmente minoritarios, a través de su forma de "ser" y de "actuar" en la dinámica cotidiana propia de la enseñanza diaria. La investigación y la teoría analizada en este artículo muestra cómo los profesores pueden - y deben-contribuir poderosamente a lograr una afectiva y social integración escolar de esta categoría de alumnado a través de las mil interacciones positivas diarias mantenidas con estos alumnos. También se pone claramente de manifiesto que los datos analizados deben contribuir, sobre todo, a despertar la conciencia profesional de los profesores a fin de capacitarlos para ser reflexivos, sensibles y comprometidos con la suerte escolar de este tipo de alumnado minoritario. En definitiva, la tesis central encerrada en este artículo es que los profesores resultan ser "los instrumentos por excelencia de los instrumentos pedagógicos", también para conseguir una genuina integración escolar de este tipo de alumnos diferentes.

Descriptores: educación intercultural, alumnado culturalmente diferente, integración escolar, influencia del profesorado, responsabilidad profesional. 


\section{SUMMARY}

This study carries out an analysis of the great influence that teachers have on the school integration concerning culturally minoritary students, both through the way they "are" and the way they "act" in the daily dynamics characteristic of ordinary teaching. The research and theory analized in this work show how the teachers can - and must - contribute strongly to the affective and social school integration of this kind of students in the thousand and one daily positive interactions with these students. Also it's strongly suggested that the data analysed should contribute to awaken the professional conscience of teachers in order to form a moral and professional responsibility in them that qualifies them to be reflective, sensitive and committed with this kind of minoritary students. In short, the central thesis which lies behind this paper is that the teachers are "the better instruments of the pedagogical instruments" for get a genuine school integration of these different students.

Key words: intercultural education, culturally minority students, school integration, teachers' influence, professional responsability.

\section{INTRODUCCIÓN}

Este estudio no se centra en posibles estrategias didácticas u organizativas que pueden ser más o menos exitosas a la hora de integrar lingüística, académica y socialmente a alumnos de otros contextos culturales que se incorporan a nuestras escuelas. No faltan en esa dirección, más pautada y expresa, interesantes experiencias y orientaciones, como pueden ser - entre otras- las conocidas y también debatidas "clases de acogida" francófonas (Glenn, 1992).

Esta aportación tampoco se centra en formas "externas" de integración del alumnado minoritario en la estructura y dinámica escolar. Por lo demás, en el caso de contemplar el objeto de nuestro análisis desde una perspectiva educativa de tipo político-organizativo, podría decirse que, en cierto sentido, esa categoría de alumnado ya está "integrado" en nuestras escuelas ${ }^{1}$, al no haber en nuestro país escuelas ni aulas especiales, "segregadas", como en su tiempo fueron - por ejemplo- las escuelas puente para gitanos; si bien es cierto que si ahondamos tan sólo un poco en ese terreno, continuaremos encontrando realidades escolares marginales, centros conformados prioritaria o exclusivamente por alumnado minoritario excluido, debido a causas sociológicas bien conocidas ${ }^{2}$. Con todo, no será éste nuestro objeto de indagación, por más neurálgico que sea este problema.

1. La actual legislación en materia de inmigración deja bien clara — tras discutidos zigs-zags sociopolitícos- la escolarización de los niños y adolescentes de padres inmigrantes, incluso cuando éstos se hallen en situación de ilegalidad, siempre que estén empadronados; lo que hace que, al menos desde esa perspectiva global, la "integración escolar externa" esté aún más asegurada.

2. Este fenómeno no es simple. No todas las escuelas monoculturales con alumnado minoritario son precisamente guetos. Pensemos en el Liceo Francés, el Colegio Alemán, el Instituto Británico..., por 
¿Cuál es, pues, la intención focal de nuestra concreta aportación? Podríamos responder que, fundamentalmente, no es otra que la de poner de relieve cómo las actitudes, las conductas y —en general— toda una serie de sutiles mecanismos formales e informales propios del ser y del quebacer de los profesores que tienen a este tipo de alumnos contribuyen a su integración socioafectiva escolar.

Porque, ¿bastará la simple coexistencia externa de alumnos diferentes para lograr objetivos tan deseados como la apetecida convivencia y la integración escolar? La práctica y la teoría nos dicen, obviamente, que no: desde Allport (1954) hasta Triandis (1988), por nombrar dos hitos claros de la abundante investigación al respecto, se ha constatado que, a menos de mediar una serie de factores psicopedagógicos oportunos, el contacto se torna en una circunstancia precisamente negativa en relación a objetivos tan deseables como los citados desde el punto de vista intercultural.

El siguiente texto de H. C. Triandis nos puede servir para comentar la importancia de nuestro propósito:

"En una variedad de situaciones de todo el mundo, el simple contacto ha contribuido más bien a incrementar los prejuicios. Esta constatación quizás sea demasiado dura, pero resulta consistente con los datos que la investigación nos proporciona siempre que se da una diferencia de status significativa entre los grupos en contacto [...] Así, por ejemplo, muchos de los profesores, médicos y enfermeras que han trabajado en Alaska con esquimales han acabado desarrollando más estereotipos negativos hacia ellos que otras personas que han tenido poco o ningún contacto con esta minoría" (Triandis, 1988: 89).

Lo que no acaba de explicar Triandis es que esos profesionales - entre los que había profesores- iban en ese caso con el objetivo de enseñar o de prestar ayuda médica, pero no con la conciencia despierta, formada y debidamente sensibilizada para perseguir fines más ambiciosos: intentar alcanzar objetivos interculturales tales como, por ejemplo, el fomentar una interacción mutua y simétrica enriquecedora entre ellos y las personas esquimales con las que se relacionaban diariamente.

Ése es precisamente el reto que tienen nuestros profesores cuando acogen en sus aulas alumnos minoritarios: lograr la afectiva y efectiva integración escolar de

poner algunos ejemplos. Con todo, no puede obviarse el hecho de una estratificación socioeducativa excluyente en gran parte de los contextos escolares en que abunda alumnado minoritario de bajo status socioeconómico. Aparte de la guetización étnica de carácter urbanístico, laboral y vecinal, existe el triste fenómeno de la conformación de guetos escolares "artificiales" a causa, en gran medida, de la deserción del alumnado autóctono o mayoritario de aquellos centros educativos en que son elevados los porcentajes de alumnado étnicamente distinto y hacia el cual se proyectan estereotipos y prejuicios tales como su potencial conflictividad, bajo rendimiento escolar... y, en el fondo, la incomodidad interior de vivir con los "diferentes". Una crítica acertada y directa a este fenómeno de la guetización escolar artificial respecto a los alumnos minoritarios puede leerse en el artículo de Teresa SAN ROMÁN (1998): "Escuelas y relaciones interétnicas". En SANTAMARíA, E. y GONZÁLEZ, F. (coords.): Contra el fundamentalismo escolar. Virus Editorial, Barcelona, pp. 73-89. 
estos niños mediante formas oportunas de actuar e interaccionar con ellos. Porque, por adelantar un ejemplo en este sentido, ¿acaso no pueden contribuir los profesores en gran medida a "igualar el status" de sus alumnos culturalmente distintos y, a menudo, socialmente distantes? La respuesta es evidentemente afirmativa, siempre y cuando tengan una preparación y un compromiso educativo básico de orientación claramente intercultural.

Las propuestas de Jim Cummins (1987) van en esa línea. Dado que este tipo de alumnado - argumenta ese autor - suele estar más bien marginado y devaluado socialmente, el profesorado debería invertir, a través de toda medida posible, tal asimetría dentro de los muros de la escuela, en lugar de reproducir de forma mimética las experiencias negativas que viven esos niños o jóvenes en la cotidianidad real. Una de las formas, entre otras, de invertir las relaciones intraescolares del alumnado minoritario a su favor, a fin de igualar el status, podría ser la valoración genuina y pragmática, dentro de la vida escolar diaria, de aspectos relevantes de su cultura, como, por ejemplo, su lengua originaria. Resaltar — cuando no es fáctible su inclusión curricular- el valor de sus lenguas, de modo que resulten incluso funcionalmente importantes en nuestro contexto socioescolar es algo que un profesorado con conciencia clara de su protagonismo profesional puede hacer muy a menudo: mostrando el origen árabe -y no sólo latino- de nuestra lengua..., o utilizando la lengua minoritaria como recurso de primera importancia para recabar información viva (a través de lectura de diarios o audiciones radiofónicas pertinentes, por ejemplo) a fin de tratar así ciertos temas relevantes [históricos o actuales] de ciencias sociales de forma completa y equilibrada.

\section{Ciertos datos negativos de UnA PARTE DEL Profesorado}

Antes de exponer algunas de las posibilidades que tienen en sus manos los profesores a la hora de integrar oportunamente al alumnado minoritario, puede ser conveniente traer a colación algunos resultados de numerosos estudios sobre las actitudes que adoptan, con cierta frecuencia, un número significativo de ellos. El objetivo de este a partado no es, por supuesto, recriminar al profesorado (normalmente tiene, como mínimo, una voluntad positiva respecto a la atención de este tipo de alumnado), ni abonar una postura pesimista. Todo lo contrario: el propósito de los datos que siguen es despertar la necesidad de tomar una conciencia mayor de la trascendencia de esas actitudes - frecuentemente no conscientes-y de la conveniencia, si es el caso, de "re-socializarlas" desde la perspectiva pedagógica propia de una positiva educación intercultural.

En todos los países estudiados ${ }^{3}$ sucede que un porcentaje significativo de profesores reproducen en el ejercicio docente los esquemas deformados que laten en

3. Una visión más amplia de estudios o investigaciones relativas a la percepción que tiene el profesorado del alumnado minoritario que tiene en sus clases, desde una abanico representativo de distintos 
el inconsciente cultural de nuestras sociedades, interiorizados "naturalmente" a través de la inmersión en ese clima sociocultural cotidiano ${ }^{4}$.

En una investigación extensa, el profesor Calvo Buezas (1990) encontró que, después de preguntar a 1.100 docentes si les gustaría tener en clase alumnos de otras culturas, la media de respuestas negativas fue el $9 \%$, pero los alumnos que se llevaron más rechazos fueron los gitanos; en concreto, el 25\% de los docentes manifestó que no les agradaría tener alumnos de esta etnia vecina en clase. Estos resultados pueden ser interpretados de forma aún más preocupante si se piensa que las respuestas a instrumentos como los cuestionarios no suelen ser el fiel reflejo de las que realmente existen en las capas más hondas del psiquismo; en ese sentido, ese tipo de respuestas podrían ser solamente una parte importante de un iceberg afectivo marginador de mayor bulto.

¿Cómo podemos interpretar esos datos según el propósito de este trabajo? Desde luego, si los resultados anteriores fueran así de reales, no pocos profesores tenderían a mostrar en la práctica docente diaria actitudes y conductas más bien negativas hacia no pocos alumnos minoritarios: por ejemplo, en forma de sutiles comentarios negativos informales dirigidos a estos niños acerca de su forma de actuar en clase o de realizar ejercicios académicos ${ }^{5}$.

Eso es lo que se constata en una investigación muy divulgada, convertida casi en clásica sobre este tema, llevada a cabo por D. Zimmermann (1978). Su objetivo fue estudiar el grado de "atracción-repulsión" que tenían los profesores hacia alumnos minoritarios en algunos centros escolares franceses. Después de pasar cuestionarios a los docentes con ítems como: "este niño es muy agradable", "es simpático",

países puede verse en nuestro libro: JORDÁN, J. A. (1998a): La escuela multicultural. Un reto para el profesorado. Paidós, Barcelona.

4. Trasladándonos a la historia, este fenómeno se percibe a modo de anécdota en la reconocida figura de Shakespeare. En su obra El mercader de Venecia, este autor presenta al judío como una persona sin corazón, avariciosa y cobarde. ¿Acaso tuvo el célebre literato experiencias negativas reales con los judíos? La respuesta es, obviamente, negativa; pues los judíos habían sido expulsados de Inglaterra hacía más de 300 años. El único contacto que tuvo Shakespeare con los judíos fue a través del estereotipo todavía vivo en su cultura anglosajona. En una línea parecida, no pocos profesores, antes de llegar a ser profesionales de la educación, han estado inmersos en un clima cultural abundante en prejuicios, estereotipos, y juicios etnocéntricos. De ahí que, hasta los más comprometidos con el ideal de una genuina educación intercultural manifiesten con frecuencia que tienen que "forcejear" con sus actitudes inconscientes para no dejarse arrastrar por ellas a la hora de pensar y actuar de acuerdo a sus deseados principios conscientes interculturales (BLRSTEIN y CaBELLO: 1989).

5. En una investigación etnográfica, A. VASQUEz (1984) anotó en una escuela francesa que la profesora observada se dirigía mucho más a los niños de origen latinoamericano (218 interacciones) que a los autóctonos franceses (48). Pero, lo más lamentable es que cuando se dirigía a los niños diferentes era, sobre todo, con un tono devaluador (críticas, subestimación, regañinas..., ciertos castigos), y muchas más veces (178) con esa orientación negativa que con otra de carácter positivo y estimulante (sólo 43 interacciones de este último tipo). Estos resultados hablan por sí solos, aunque sería abusivo generalizarlos a la mayoría de profesores que tienen alumnos minoritarios; como también sería pesimista pensar que poco se puede hacer para cambiar ese tipo de actitudes y comportamientos. 
"me es indiferente", "me cae antipático", y "me provoca rechazo", aplicó en la segunda fase de su investigación una metodología de tipo cualitativo: concretamente, una observación participante. Los resultados - decepcionantes- fueron sintéticamente los siguientes: al referirse al alumnado minoritario, los datos correspondientes a los ítems negativos resultaron ser abundantes; a veces, hasta llegar a alcanzar una frecuencia del 30\% en algunos de ellos (por ejemplo, en el de «indiferencia"). La observación constató -y esto quizás es lo que tiene más importancia- que la falta de ciertos prerrequisitos académicos, la poca higiene, la mayor movilidad, así como ciertas conductas vinculadas a su cultura diferente, provocaba en bastantes de los profesores estudiados reacciones y comportamientos, sobre todo "no-verbales" (gestos de desagrado, miradas de indiferencia, silencios reprensivos..., o distanciamientos evasivos), que - en palabras del propio Zimmermann- contribuían a conformar verdaderos guetos psicológicos para los minoritarios de aquellas aulas, dado el rechazo sutil, la indiferencia y la falta de vínculo afectivo que se vehiculaban a través de ese tipo de reacciones negativas.

La pregunta que surge a partir de datos como los anteriores es la siguiente: si dichas actitudes y reacciones más bien larvadas no se auto-analizan y se modifican, ¿no estarán fomentando ese tipo de profesores situaciones escolares segregadoras, más graves todavía que los guetos visibles de tipo externo? Pero, además, ¿tal segregación y rechazo psicológico no hipotecará toda una serie de logros académicos, lingüísticos... y, por supuesto, afectivamente integradores? Lo lógico es pensar que así suceda si esos fenómenos negativos llegan a cristalizar en ciertos docentes, dado el clima enrarecido generado por ese tipo de interacciones, tan poco propicio para el interés por el aprendizaje como para el deseo de integrarse realmente.

\section{AlgUNAS REFLEXIONES SOBRE EL PROTAGONISMO DEL PROFESORADO}

A menudo se dice que la escuela, y más en concreto el profesorado, puede influir relativamente poco en la personalidad de los niños y jóvenes, siendo otras fuerzas sociales mucho más poderosas. No es ése nuestro parecer; al menos no comulgamos con esa visión apocada y restringida de la influencia escolar.

Se habla, en este sentido y por ejemplo, mucho del bombardeo de los medios de comunicación en la conformación del inconsciente de los receptores. No lo dudamos. Pero, ¿es mucho menor el flujo de mensajes sutiles que impacta en las mentes de nuestros alumnos cuando están en la escuela? Según los cuidadosos registros de Ph. Jackson (1990) sobre las interacciones personales -verbales o no- que acontecen en el aula, los niños están expuestos a una lluvia de 200 mensajes por hora; es decir, un total de 1.000 por día, de 250.000 al año y —más o menos- de unos 3.000.000 a lo largo de la escolaridad obligatoria. A partir de estos datos nos es difícil dudar de la potente influencia de la escuela y del protagonismo del profesorado, también en el campo de la interculturalidad.

Lo que importa ahora es si tales interaccciones, cuantitativamente inmensas, son o no de tipo positivo; si van depositando - ¿o no? - en las profundidades del 
psiquismo de los alumnos vivencias realmente educativas, en nuestro caso desde el punto de vista pedagógico intercultural.

Algunos datos más en esta dirección pueden ser útiles para tomar conciencia de la importancia del protagonismo del profesorado en el campo que nos ocupa. Leamos un fragmento de un artículo de Jacqueline Jordan al respecto:

"El protagonismo que tiene el profesor en las vidas de los ahumnos minoritarios es proporcionalmente mayor que en el caso de aquellos mayoritarios de clase media. Los primeros, en efecto, tienden a identificar más al profesor como una figura muy significativa, de forma que su autoconcepto está en gran medida determinado por cómo ellos sienten que sus educadores los perciben y tratan. Así, los alumnos que sienten que sus profesores no los aceptan de forma positiva, con frecuencia tampoco se valoran a sí mismos ni a la escuela; se sienten marginados y desanimados, y a menudo fracasan escolarmente" (Jordan, 1988: 506-507).

El mensaje de esta autora, dicho de forma abreviada, sería el siguiente: el tipo de alumnos minoritarios en quienes estamos pensando (inmigrantes de clase baja) se perciben a sí mismos, tanto en la sociedad como en la escuela, con notoria frecuencia devaluados, marginados o segregados. A ese status social y psicológico inferior, y de evidente dependencia, hay que añadir —además — una visión del maestro como un adulto con autoridad moral y escolar, sobre todo por parte de los alumnos de los contextos socioculturales que todos tenemos en mente. La conclusión, siempre general, no puede ser más lógica: la influencia del profesorado sobre este tipo de alumnos es doblemente negativa o positiva en lo que se refiere a aspectos tan cruciales como su autoconcepto, su interés por la escuela, su rendimiento académico, su madurez psicológica y, más globalmente, su deseo y su plasmación real de integrarse socioafectivamente en la vida escolar; paso decisivo, por lo demás, para una integración sólida y equilibrada social de más amplio espectro ${ }^{6}$.

\section{4. ¿QUÉ PUEDEN HACER LOS PROFESORES?}

Teniendo siempre presente que lo que nos interesa en este estudio es resaltar cómo el profesor puede influir en la integración del alumnado minoritario que se incorpora a nuestras escuelas, comentaremos a continuación algunas de las formas en que puede hacerlo de forma incisiva.

6. En esta línea van también los estudios de R. Rosenthal y L. JaCOBSOn (1980), Ph. JACKSON (1990), A. Pigford (1992), entre otros. Puede verse para mayor detalle el capítulo segundo de Jordán (1998a). 


\subsection{La práctica de una "pedagogía del reconocimiento"}

Si lo que se desea es que los alumnos minoritarios se integren - sin asimilarlos- en la dinámica escolar, una forma privilegiada de hacerlo es a través del reconocimiento por parte del profesor de la persona y de la identidad cultural de cada uno de ellos.

Un comentario de un profesor que tenía alumnado de este tipo puede ser muy ilustrativo en este sentido:

"La escuela ha de integrar a estos niños en la cultura en que viven ahora, y debe enseñársela; pero sin olvidar que tienen una cultura propia y que no ha de ser anulada. Cuando alguien siente rechazo bacia lo propio difícilmente se puede integrar en lo ajeno" ${ }^{7}$.

Principio, éste, validado y contrastado por diversas investigaciones llevadas a cabo sobre esta temática. Pensemos, aunque sea brevemente, en la problemática identidad cultural de los adolescentes de "segunda generación" de inmigrantes. Por regla general, aunque éstos se sienten ligados a la cultura propia de sus padres (especialmente por el vínculo afectivo que les une a ellos), esos jóvenes tienden generalmente a integrarse en la sociedad y cultura del país de acogida. El sentirse acogidos por sus iguales de colegio y barrio, así como el querer gozar de elementos socioculturales positivos del contexto en que realmente viven bic et nunc, les impulsa, ciertamente, a integrarse en el nuevo hábitat de una forma psicológicamente más honda si los comparamos con sus padres; lo cual no quiere decir que esa apetecida integración la deseen a cualquier precio (por ejemplo, a costa de despojarse de todo elemento cultural de su referencia primera). Ahora bien, tal proceso de integración no cuaja felizmente a menos que sientan que su cultura "de origen" es también reconocida o valorada mínimamente de algún modo. De no ocurrir así, la reacción común en muchos casos es encapsularse más en la cultura heredada de sus padres ${ }^{8}$.

7. Es un comentario recogido en nuestra investigación con profesores sobre esta temática. Ver J. A. JORDÁN (1998a: 131).

8. Jim Cummins (1987), en un plano relativamente próximo, asegura que llegar a ser un sujeto bilingüe no es una pobreza sino una riqueza personal, al poder integrar naturalmente dos códigos lingüísticos. Pero se ha de dar una condición, que él denomina ley de la interdependencia psicolingüística"; según ésta, alguien puede aprender bien una segunda lengua (L2) a condición de tener un dominio "elaborado" suficiente de la primera lengua (L1), bagaje que se transfiere en gran parte al aprendizaje de la nueva lengua. En el mismo terreno del multilingüismo, J. HaMers y M. BLANC (1989: 127) muestran cómo, en el mismo terreno de la educación multilingüe, se da también otra condición: la de una "interdependencia cultural"; la que describen de forma sintética así: «una pobre identificación con la cultura materna correlaciona con una falta de identificación con una segunda cultura"; o dicho de otro modo: "cuanto más positivamente percibe una persona su propia cultura, tanto más favorables son sus actitudes hacia otro grupo cultural distinto"..., tanto más fácil es —en definitiva - una saludable integración social, cultural y lingüística.

Este fenómeno también se da a la inversa: es muy difícil valorar una cultura ajena (por ejemplo la marroquí por parte de los catalanes, o la catalana por parte de los marroquíes) sin que la propia identidad cultural sea razonablemente valorada (ver J. LADMIRAL y E. LIPIANSKY, 1989: 171). 
Peter Berger, refiriéndose a este fenómeno - a la pertinente integración en una nueva realidad cultural- insiste convencidamente: "esto sólo es posible si el contexto social esta dispuesto a reconocer ese deseo" (1988: 143). Cuestión de enorme importancia pedagógica, pues ¿cómo asegurar la integración escolar, por ejemplo, de un alumno inmigrado, que desea ser uno más entre sus iguales, a menos que éstos, los profesores y toda la globalidad de las cotidianas vivencias escolares apoyen cálidamente su gran esfuerzo por modificar en buena parte su identidad de referencia primaria?

Es en este plano cuando resulta inteligible la cabal tesis de Teresa Losada, al afirmar — desde su acendrada experiencia con esa franja juvenil marroquí- la necesidad de reconocimiento social, cultural y personal para los jovenes de segunda generación de inmigrantes.

"El reconocimiento social es la mejor pedagogía para la integración sociocultural de estos jovenes inmigrados. Las raíces reales de ellos están donde esté la comunidad [que bien los acoja], donde esté su red de relaciones personales [positivas], donde encuentre sus solidaridades [sinceras]..., [en síntesis], su porvenir" (1990: 245).

Desde una perspectiva más escolar, el reconocido antropologo francés Carmel Camilleri nos recuerda - a través de un vivo ejemplo- esa necesidad siempre imperante de reconocer a los alumnos diferentes y minoritarios. Pensemos en su narración del siguiente caso:

"Armindo, un niño portugués inteligente de once años, estaba muy angustiado a causa de su fracaso en la escuela francesa. Este síndrome desapareció, sin embargo, cuando un día la psicóloga le pidió que hiciese una prueba, pero en su lengua materna. "Tú hablas portugués y yo lo entiendo", le dijo esta profesional. Armindo, antes avergonzado de su lengua y cultura, "estaba enfermo de identidad". Después de esta experiencia, Armindo cambió de conducta, mejoró su rendimiento académico, era feliz en clase, hablaba de su vida privada y, al cabo de dos años, podía ya resolver cualquier ejercicio escolar en lengua francesa" (1985: 196).

En este caso, la psicóloga — como lo podía haber hecho cualquier profesor- se limitó tan sólo a captar la raíz del problema de ese niño inmigrante y a responder con solicitud pedagógica a través de una actuación tan sencilla como trascendente: supo reconocer el sentimiento de inferioridad cultural que ese alumno tenía en medio de un grupo o clase formado sobre todo por compañeros autóctonos. Otros profesores, por supuesto, según sean los casos y circunstancias, pueden poner en marcha formas de reconocimiento distintas; pero lo esencial permanece en este sentido inalterable. El fin es, en definitiva, el mismo. Así nos lo narra el propio niño en una confesión a la psicóloga que lo atendió: "yo no sé qué me ha sucedido, pero ahora todo ha cambiado; me siento feliz en la escuela.

Pero, ¿cómo puede el profesor manifestar reconocimiento? Sugerimos sólo algunas formas, por lo demás, tan sencillas como efectivas. 
Supongamos el caso de Fátima, una muchacha magrebí de catorce años que aprovecha en el plano académico y que, además, ha manifestado varias veces que le gustaría estudiar de mayor alguna carrera relacionada con la medicina. Por motivos culturales, Fátima lleva faltando dos semanas a la escuela, pues algunos días de estas semanas su curso ha salido de colonias, cosa que no les ha parecido bien a sus padres. Su tutora duda si debería aplicar con ella la misma normativa disciplinaria vigente para los casos de absentismo prolongado "no justificado", aprobada hace un tiempo en el Reglamento de Regimen Interno. Además, algunos docentes colegas suyos le han sugerido que todos deberían ser tratados igual. Un martes aparece de nuevo Fátima en clase; su rostro muestra más bien vergüenza; da a la tutora algunas entrecortadas razones sobre su ausencia, sin querer poner en evidencia a sus padres, con sus pricipios culturales diferentes a los escolares en ciertos puntos. La profesora, movida por una intuición solícita hacia la persona de Fátima no habla nada con ella sobre el asunto de su ausencia; por el contrario, le muestra una sonrisa que expresa toda una carga de alegría por haber retornado a la escuela su alumna marroquí. Se da cuenta, a partir de ese momento, que Fátima se relaja y muestra el alegre interés por la escuela que hace quince días tenía. Sin duda, ha sentido comprensión, aceptación y, de forma menos directa, reconocimiento en relación, no sólo hacia su persona, sino también a su referente cultural familiar. En lo sucesivo, se muestra más implicada en los estudios, más confidencial con su tutora, más integrada en la escuela, concebida ahora para ella como un lugar acogedor.

En el caso descrito, ¿no se hubieran producido efectos seguramente contrarios si la profesora hubiera actuado impulsada por un falso y frío "trato igualitario"? ¿No habría experimentado en ese caso Fátima la sensación de sentirse - también en la escuela - incomprendida, etiquetada y rechazada por razones culturales, con algunas de las cuales quizás tampoco ella esté plenamente de acuerdo? ¿Desde un punto de vista pedagógico, el "trato igualitario simple" no habría podido malograr el proyecto académico-vital de esa muchacha??.

\subsection{Tras una "pedagogía de la solicitud"}

Otra de los dispositivos que puede - y debe- poner en funcionamiento el profesorado que tiene a este tipo de niños es practicar lo que actualmente viene denominándose como pedagogía de la solicitud. Con esta expresión, u otras similares, se desea recordar que el profesor ha de tomar conciencia de su compromiso

9. Idea retomada de Nel Noddings (1986), artículo en donde defiende que el profesor debe interesarse de forma profesionalmente responsable de todos y cada uno de sus alumnos, viéndolos como "personas reales y singulares", con toda su circunstancialidad. Es interesante, en este sentido, remarcar que para esta autora todos los alumnos distintos - sea cual sea el motivo de su diferencia- deben poder sentir por vías, no necesariamente verbales, un yo te sigo queriendo ayudar como profesor/a, pues me siento responsable de tu formación. 
con la suerte educativa de todos y cada uno de sus alumnos, en virtud de una responsabilidad ética derivada de su profesionalidad.

Desde esta perspectiva - que no responde a una ideología pedagógica estrictamente nueva, sino que más bien se limita a "recordar" el alcance de la función propia de todo profesor- ya no se admite que el profesor limite su relación con los alumnos al esquema de mediador o gestor de los aprendizajes de estos últimos. Si así lo hiciera, su actuación no diferiría, en esencia, de la de un comerciante con sus clientes o, recordando el pasado, de la tarea llevada a cabo por los sofistas griegos, "que vendían su saber a cambio de dinero". Según este esquema reductivo, el criterio regulador de la relación profesor-alumno no sería otro que el de la eficacia respecto a los aprendizajes logrados por sus alumnos. Por ejemplo, un profesor de Educación Infantil podría estar tentado, en sintonía con ese enfoque limitado, a conseguir aprendizajes precoces en el terreno de la lectura a través de metodologías didácticas exitosas ya existentes ${ }^{10}$, en vez de valorar la conveniencia (o no) de aplicar tales técnicas y lograr dichos aprendizajes con el metro - ahoradel desarrollo de la personalidad global de sus alumnos.

En el esquema referido anteriormente, los valores y actitudes pedagógicas subyacentes son aquellos de eficacia y de éxito, manejando una concepción del alumno unilateral y, en definitiva, objetual. Por el contrario, la pedagogía de la solicitud se centra en la persona del alumno considerada en todo su respeto y en toda su totalidad. Más concretamente, y para lo que aquí y ahora nos interesa, el centro de atención en el caso de los alumnos inmigrantes es su condición sustantiva de personas, considerando sus características culturales de forma más adjetiva y circunstancial..., importantísimas si se desea poner también el foco de la atención pedagógica en ellas, pero, al fin y al cabo, con un valor sobreañadido, en modo alguno esencial ${ }^{11}$.

Pero, ¿qué consecuencias tiene todo esto para el tema que aquí abordamos? Probablemente más de las que podríamos pensar a primera vista. Anotaremos aquí, por economía de espacio, sólo un par de ellas.

10. Para mayor ampliación sobre este tema concreto baste citar las publicaciones siguientes: R. COHEN (1983, 1986); Gl. Doman (1981), G. MEdrano (1985). En esta línea, puede ser conveniente anotar que, a veces, también los padres corren el peligro de caer en la tentación de "educar" a sus hijos bajo el patrón prioritario de la eficacia. ¿No actúan así aquellos que buscan con afán —aunque seguramente de forma involuntaria - el que sus hijos destaquen en algún aspecto aplaudido por nuestra sociedad o cultura: por ejemplo, en el plano deportivo, musical, lingüístico, etcétera; "forzando" así a los niños a realizar una sobrecarga de aprendizajes que deforman, más o menos, el desarrollo equilibrado y global propio de su infancia o juventud?

11. Este filón es de suma importancia a la hora de fundamentar una educación intercultural equilibrada, pues supone dejar de considerar al ser humano, única y simplemente, como un "animal cultural. Léanse, con espíritu crítico, las tesis de fondo que sostiene Cl. GEERTz (1990), entre otros. Nuestra posición, al menos, es que al ser humano hay que entenderlo en calidad de "persona" —en toda su profundidad ontológica y psicológica - moldeada más o menos intensamente por la[s] cultura[s] en que se desarrolla. Baste esta consideración para este momento. 
Tal y como apunta Max van Manen (1998: 152-153), "todo ser humano es mi otro. Siento al otro como una voz, como una llamada, que me impele a estar orientado en la práctica [educativa] hacia él". El "otro" - sea éste quien fuere: un niño catalán o uno argelino- es, desde esta óptica, quien invita al profesor en su práctica diaria a salir de su visión egocéntrica y, si es el caso, de su punto de mira etnocéntrico, ya que en la cotidianidad de las relaciones más sencillas que ocurren en la vida escolar ordinaria la persona del alumno - centro y metro de toda la acción educativa- reclama una atención y un reconocimiento de todas las fibras que tejen su personalidad en formación. Un reclamo que, cuando es secundado profesionalmente por el educador, lleva a una acción educativa coherente con el verdadero bien educativo de la persona del alumno. El mismo Max van Manen salpica su magnífico libro de ejemplos prácticos en esa dirección. Apuntamos aquí, por ejemplo, el siguiente:

"Era una niña marginada por sus compañeros de clase. Un día fue duramente insultada. Ella se quedó quieta, con los hombros encogidos, la mirada caída y sollozando calladamente. [Estaba necesitada de apoyo moral]. Puse mi brazo alrededor de ella, mientras le hablaba con afecto. Poco a poco, recobró la calma. Aquel incidente me había hecho caer en su necesidad de verse acogida, valorada, reconocida. Al mediodía descubrí una breve nota en mi mesa: "iGracias por su atención..., ahora ya me siento bien!". Al acabar el día, algunos de sus compañeros se me acercaron y, tímidamente, me preguntaron si ellos también podían hacer algo para reparar el desagradable incidente" (p. 153).

Lo importante en todo esto es que los alumnos no sólo aprenden matemáticas, inglés o literatura; ellos captan ${ }^{12}$ — a través, además y por encima de todo eso- las innumerables lecciones de valoración-indiferencia, aceptación-rechazo..., y equidad-injusticia inscritas en la vida diaria escolar. Los alumnos, desde las edades más tempranas, captan ciertamente - también por la vía no verbal de la voz, la mirada..., o la cercanía - si son aceptados e integrados en su calidad de personas circunstanciadas, o si por el contrario, aunque sea de forma larvada, son más o menos rechazados y segregados respecto a la cultura del aula o de la escuela en la que pasan una gran parte de su vida real. Si eso es así, ¿por qué no reflexionar más sobre el positividad o negatividad pedagógica de las reacciones "rutinarias" de nuestro quehacer como profesores cuando enseñamos; $y$, sobre todo, en el terreno que aquí nos interesa; es decir, cuando se ejerce la docencia con alumnos minoritarios,

12. Max VAN MANEN (1998: 213) nos recuerda a nota de página la interesante tesis de PolanY (1983): a través del conocimiento personal tácito, también los niños "Saben más de lo que pueden expresarn; es decir, asimilan mucho más de forma no consciente acerca de las influyentes reacciones de los mayores que están a su lado, de lo que podemos suponer y de lo que ellos pueden exteriorizar con sus palabras. Y en un terreno más práctico, V. PALEY (1989) comenta: "Qué importa si un niño negro acaba identificándose étnicamente con una maestra judía? Si la maestra lo acepta y lo aprecia como es, y por lo que es, ¿no es ya suficiente?". 
ya devaluados? Sólo a partir de ese acto autorreflexivo, el profesional de la educación quede quizás asombrado de que ciertas interacciones, llevadas a cabo con tacto solícito, tienen la virtualidad de cambiar la ruta negativa de un alumno dirigido inertemente al fracaso personal, escolar y social. ;Tremenda, la influencia de un profesor ética y profesionalmente comprometido!

Otro aspecto interesante en este sentido es que los impactados no sólo son, en nuestro caso, los alumnos inmigrantes, sino también los autóctonos. También ellos, en efecto, aprenden la calidad de las reacciones que tiene el profesor con sus iguales minoritarios. Las actitudes interculturales de acogida, apertura, respeto y tolerancia que se desea que adquieran los alumnos autóctonos en relación a sus compañeros diferentes, las aprenderan más a través del impregnarse una y otra vez de esas actitudes vividas por los profesores que mediante la aplicación de estrategias proveniente de la más refinada teoría científica pedagógica ${ }^{13}$. Como la piedra que cae en el estanque y produce ondas concéntricas, parecidamente ocurre con los alumnos autóctonos, quienes también quedan indudablemente tocados por las actitudes practicadas por parte del profesor en sus relaciones más directas con los alumnos minoritarios ${ }^{14}$.

Sin salirnos del protagonismo del profesor, el filón de la influencia que - además de la recibida por los adultos- también pueden ejercer los compañeros de clase es de suma importancia. Nos bastará aquí mostrar algunos comentarios y hallazgos de la investigación etnográfica llevada a cabo por A. Vasquez e I. Martínez (1996), precisamente sobre los procesos de integración de alumnos diferentes:

"Los alumnos saben perfectamente que van a la escuela para hacer un aprendizaje "serio" y, aunque aceptan este objetivo, a nivel de la cotidinidad sienten que'lo más importante es la vida social que se desarrolla en la escuela" (p. 132). "Los niños de los inmigrantes, conscientemente o no, se percatan de que están situados en el lado de los desposeídos de poder. En esta situación, los lazos afectivos, o sea los de los amigos, les resultan aún más necesarios" (p. 141). "Si el maestro percibe el alcance que las interacciones amistosas tienen para el desarrollo y la integración de los

13. Véase, a este respecto, F. CARBonell (1995: 140). Como nos hemos propuesto al comienzo de este trabajo, no abordaremos aspectos organizativos que fomenten la integración de los inmigrantes que se incorporan a nuestras escuelas. Con todo, aquí nos interesa recordar que para algunos investigadores críticos, ciertas formas de acogida — clases especiales - llevadas a cabo en varios países les resultan bastante insuficientes porque dejan al margen la actitud integradora del profesorado. Tanto los docentes que están en aulas ya "normalizadas" (con alumnos inmigrantes que ya han conseguido ciertos prerrequisitos básicos de tipo académico y lingüístico) como los que están en las mismas clases "especiales", pueden seguir funcionando con creencias y actitudes en el fondo segregadoras. Es por esto por lo que Ch. GLENN (1992: 408) llega a comentar: “En último término, una sensibilidad, un compromiso y un considerable esfuerzo en pro de la plena integración de los recién llegados son, quizá, más importantes que cualquier modelo organizativo adoptado".

14. Ver M. BANY y L. JOHNSON (1973: 220) para una mayor ampliación sobre esa influencia "vertical-horizontal" del profesor sobre los "demás" alumnos no directamente implicados en una relación educativa determinada, especialmente cuando está cargada de significaciones valorativas o morales. 
niños minoritarios, ofrecerá oportunidades para que esas relaciones puedan ir cristalizando: por ejemplo, poniendo a ciertos niños juntos o encargando a determinados alumnos que hagan también de forma conjunta algunas tareas" (p. 143).

La segunda ilustración que deseamos traer a colación aquí hace referencia a la influencia que tiene la figura significativa del profesor sobre los alumnos, cuando realmente es auténtico (en sus actitudes hacia el alumnado minoritario), sobre las reacciones de los niños en este campo y, más en concreto, sobre el cultivo de un clima integrador.

David Hansen (1993) pone un ejemplo muy sencillo de cómo las actitudes profundas de los profesores pueden contribuir — en ese caso, negativamente- a crear un ambiente de segregación. Pero, evidentemente, el ejemplo no es para desmoralizar, sino para estimular a los docentes a cambiar tales actitudes en el caso de que se den y para invitar a una continua reflexión sobre las "rutinas" que proceden del mismo ser personal y profesional de éstos. El ejemplo es el siguiente:

\begin{abstract}
"Elegiré - dice este autor - un fenómeno corriente utilizado usualmente en las clases: la petición a los alumnos en general, de toda la clase, de que "levanten la mano" para intervenir en dudas, preguntas, sugerencias, respuestas, etcétera. Ésta es una rutina, entre otras muchas, simple. Pero creo que ilustra perfectamente cómo las disposiciones y actitudes de los profesores hacia los alumnos en calidad de personas y de aprendices son vehiculadas a través de actuaciones aparentemente tan irrelevantes como ésta y, a la vez, tan impactantes - a nivel afectivo y moral- en la personalidad de los alumnos y en el clima de la clase. El profesor puede ignorar a ciertos alumnos que afanosamente levantan la mano una y otra vez, y que, al final, cansados de no ser atendidos, se autopercibirán como marginados. Asímismo, el profesor puede elegir (quizá sin darse cuenta) a otros alumnos más preferidos, por diversos motivos, secundando así sus deseos de intervenir levantando sus manos, y contribuyendo con esa recompensa repetida tan sencilla a que participen, aumenten su autoestima, sus deseos de aprender, y, sobre todo, a percibirse valorados e integrados en la dinámica de la clase. A partir de este ejemplo tan trivial, se puede deducir que tanto unos alumnos como otros están con ésta y muchísimas rutinas docentes diarias recibiendo constantes mensajes informales acerca de su valía como personas y como aprendices. Las actitudes, en fin, que deseamos cultivar en nuestros alumnos (respeto, justicia, cooperación, apertura, solicitud) se conforman en gran medida asi: por inmersión, a través de relaciones interpersonales con personas significativas (como es, en principio, la del profesor) teñidas de connotaciones morales".
\end{abstract}

En otra publicación suya (Hansen, 1998), el mismo autor ratifica sus tesis al respecto: los profesores están enseñando a todos sus alumnos, al mismo tiempo que contenidos académicos, otras lecciones más profundas y decisivas para sus vidas, como, por ejemplo, su propio valor (mayor o menor) como personas, la honestidad, la tolerancia, la solidaridad, la acogida incondicional...; o bien los valores opuestos. Tales lecciones son desordenadas, intermitentes, episódicas..., pero continuas. ¡Ojalá — comenta en una de sus páginas — los profesores lleguen a comprender, si 
no todas y cada una de esas reacciones tan escurridizas, sí su enorme influencia como educadores en el terreno de los valores y las actitudes! Entonces, seguramente, se tomarán su modo de actuar en clase con suma seriedad. Comprenderán - acaba diciendo- que no se pueden esperar cualidades comportamentales y actitudinales en los alumnos si ellos, como profesores, no se esfuerzan por poseerlas primero, antes de transmitirlas involuntariamente a lo largo de la jornada escolar.

\section{CONCLUSIÓN}

¿No tendrán estos datos, fruto de serias investigaciones etnográficas ${ }^{15}$, gran relevancia para el tema que en estas páginas hemos querido abordar? No cabe duda, tal como afirma José E. Abajo ${ }^{16}$, que "el que unos alumnos (minoritarios) se integren en la clase y se impliquen en los estudios requiere necesariamente una buena capacidad de identificación tanto con los compañeros como con el profesor [...]; porque, ciertamente, el profesor es, al fin y al cabo, el principal mediador del aprendizaje (y de la integración) de dichos alumnos, de modo que la afectividad hacia ellos y sus familias constituye la clave de la eficacia de su pedagogía" (1998: 83). Dicho de otro modo: la integración o la segregación de los alumnos minoritarios dependen en gran parte - en una gran parte- de que el profesorado tome conciencia de la magnitud de su influencia en su alumnado, como persona y como profesional, con sus valores y sus actitudes, con su serio compromiso en la educación de los alumnos minoritarios y con el ejercicio autorreflexivo. En definitiva, lo propiamente importante en este tema, tan central para la apetecida escuela intercultural que los tiempos nos invitan a construir a modo de reto insoslayable, no es otra cosa que el conseguir, con tanta urgencia como serenidad, aquilatar el instrumento por excelencia de todos los instrumentos pedagógicos", esto es, el profesor maduro y comprometido ética y afectivamente con todos los alumnos, pero en especial con los cultural y socialmente más desfavorecidos.

Más nítida y viva puede presentarase la tesis defendida en este artículo si traemos a colación, para terminar, una muestra autobiográfica de Albert Camus - extranjero, a fin de cuentas - acerca de la crucial influencia que tuvo en su escolaridad su recordado maestro...; elogio expresado en la carta dirigida a éste al serle concedido, en 1957, el Premio Nobel de Literatura:

15. Entre otras investigaciones de este tipo véase la recogida en la magnífica obra de Ph. JACKSON, R. Boostrom y D. Hansen (1993): The Moral Life of Schools. Jossey-Bass Publishers, San Francisco.

16. José Eugenio Abajo es miembro cualificado de la Asociación de Enseñantes con Gitanos [Colectivo de Castilla y León], con una investigación estupenda — propia de su Tesis Doctoral- sobre los factores facilitadores e inhibidores de la integración y del éxito escolar de los alumnos gitanos. Ver a este respecto, entre otras, su publicación más extensa: ABajo, José E. (1997): La escolarización de los niños gitanos. El desconcierto de los mensajes doble-vinculares y la apuesta por los vinculos sociales y afectivos. Ministerio de Trabajo y Asuntos Sociales. 


\begin{abstract}
"Cuando supe la noticia pensé primero en mi madre y después en usted. Sin usted, sin la mano afectuosa que tendió al niño pobre que era yo, sin su enseñanza y su ejemplo, no hubiese sucedido nada de todo esto. No es que dé demasiada importancia a un honor de este tipo. Pero ofrece, por lo menos, la oportunidad de decirle lo que usted ha sido y sigue siendo para mí, y de corroborarle que sus esfuerzos, su trabajo y el corazón generoso que usted puso en su tarea educadora continúan siempre vivos en uno de sus pequeños escolares que, pese a los años, no ha dejado de ser su alumno agradecido. Le abrazo con todas mis fuerzas" (Camus, 1994).
\end{abstract}

\title{
BiBLIOGRAFÍA
}

ABajo, J. E. (1997): La escolarización de los niños gitanos. El desconcierto de los mensajes doble-vinculares y la apuesta por los vinculos sociales y afectivos. Ministerio de Trabajo y Asuntos Sociales.

- (1998): "La afectividad, clave pedagógica y apuesta social”. Cuadernos de Pedagogía, 273, octubre, 80-87.

AllPoRT, G. (1954): The nature of prejudice. Addison-Wesley, Cambridge, Massachussetts.

BANY, M. A. y Johnson, L. V. (1973): "Factores del medio que influyen en las relaciones de los miembros". En VArios Autores: La dinámica de gmupos en educación. Aguilar, Madrid. pp. 213-228.

Berger, P. L. (1988): Introducción a la sociología. Limusa, México.

Burstein, N. C. y CABEllo, B. (1989): «Preparing Teachers to Work with Culturally Diverse Students: A Teacher Education Model. Journal of Teacher Education, 40 (5), 9-16.

Calvo Buezas, T. (1990): El racismo que viene: otros pueblos y culturas vistos por alumnos y profesores. Tecnos, Madrid.

CAmilleri, C. (1985): Antropología cultural y educación. Unesco, París.

Camus, A. (1994): El primer hombre. Tusquets, Barcelona.

CARBONELl, F. (1995): Inmigración: Diversidad cultural, desigualdad social y educación. MEC, Madrid.

COHEN, R. (1983): En defensa del aprendizaje precoz. Planeta, Barcelona.

Cummins, J. (1987): "L'éducation bilingue: théorie et mise en oeuvre». En OCDE: L'éducation multiculturelle. OCDE, París, pp. 323-353.

Doman, G. L. (1981): Cómo enseñar a leer a su bebé. Aguilar, Barcelona.

GEERTZ, Cl. (1989): La interpretación de las culturas. Gedisa, Barcelona.

GlenN, Ch. L. (1992): "Educating the Children of Immigrants”. Pbi Delta Kappan, january, 404-408.

Hammers, J. S. y Blanc, M. H. (1989): Bilinguality and Bilingualism. University Press, Cambridge.

Hansen, D. T. (1993): "From Role to Person: The Moral Layerdness of Classroom Teaching". American Educational Research Journal, 30 (4), 651-674.

- (1998): "Los profesores y la vida cívica de las escuelas". Revista Española de Pedagogía, 209, 31-50.

JACKSON, Ph. W. (1990): La vida en las aulas. Morata, Madrid.

(c) Ediciones Universidad de Salamanca

Teor. educ. 12,2000 , pp. 67-83 
- Boostrom, R. E. y Hansen, D. T. (1993): The Moral Life of Schools. Jossey-Bass Publishers, San Francisco.

JoRDAN, J. (1988): "An Analysis of the Problem of Disappearing Black Educators". The Elementary School Journal, 88 (5), 503-513.

JORDÁN, J. A. (1996): Propuestas de educación intercultural para profesores. Ceac, Barcelona.

- (1998a): La escuela multicultural. Un reto para el profesorado. Paidós, Barcelona.

- (1998b): Multiculturalisme i Educació. Edioc-Proa, Barcelona.

LADMIRAL, J. R. y LIPIANSKY, E. M. (1989): La Communication Interculturelle. Armand Colin, París.

LOSADA, T. (1990): «Segunda generación de inmigración marroquí. En AA.VV.: Simposium Internacional. Movimientos bumanos en el Mediterráneo Occidental. I.C.E.M., Barcelona, pp. 243-249.

MANEN, M. van (1998): El tacto en la enseñanza. El significado de la sensibilidad pedagógica. Paidós, Barcelona.

Medrano, G. (1985): "Madurez del niño y educación preescolar". Revista Española de Pedagogia, 167, 53-70.

Noddings, N. (1986): "Fidelitiy in Teaching, Teacher Education, and Research for Teaching". Harvard Educational Review, 56 (4), 496-510.

PaleY, V. G. (1989): White Teacher. Harvard University Press, London.

PIGFORD, A. B. (1992): “Solving the at-risk problem: healthy schools can make the difference». The Clearing House, 65, 156-158.

POLANY, M. (1983): Personal Knowledge. Routledge and Kegan Paul, London.

Rosenthal, R. y JaCobson, L. (1980): Pygmalion en la escuela. Marova, Madrid.

SAN Román, T. (1998): "Escuela y relaciones interétnicas". En SANTAMARÍA, E. y González, F. (coords.): Contra el fundamentalismo escolar. Reflexiones sobre educación, escolarización y diversidad cultural. Editorial Virus, Barcelona, pp. 73-90.

Triandis, H. C. (1988): "Toward Pluralism in Education". En ModgIL, S. et alii: Multicultural Education. The Interminable Debate. The Falmer Press, London, pp. 77-99.

VASQuez, A. (1984): “Rápido y bien". Los conflictos de los niños extranjeros en la escuela francesa". Infancia y Aprendizaje, 26, 95-109.

- y MARTÍNEZ, I. (1996): La socialización en la escuela. Una perspectiva etnográfica. Paidós, Barcelona.

ZimmeRMANN, D. (1978): “Un langage non-verbal de classe: Les processus d'atraction-répulsion des enseignants à l'égard des élèves en fonction de l'origine familiale de ces derniers". Revue Française de Pédagogie, 44, 46-70. 